\title{
Repurposing itraconazole for the treatment of cancer (Review)
}

\author{
RACHEL POUNDS $^{1}$, SARAH LEONARD $^{2}$, CHRISTOPHER DAWSON ${ }^{2}$ and SEAN KEHOE ${ }^{2}$ \\ ${ }^{1}$ Obstetrics and Gynaecology Department, Birmingham Women's Hospital, Edgbaston, \\ Birmingham B15 2TG; ${ }^{2}$ Institute of Cancer and Genomic Sciences, College of Medical and \\ Dental Sciences, University of Birmingham, Edgbaston, Birmingham B15 2TT, UK
}

Received January 14, 2017; Accepted April 6, 2017

DOI: $10.3892 / \mathrm{ol} .2017 .6569$

\begin{abstract}
The repurposing of drugs is becoming increasingly attractive as it avoids the lengthy process and cost implications associated with bringing a novel drug to market. Itraconazole is a broad-spectrum anti-fungal agent. An emerging body of in vivo, in vitro and clinical evidence have confirmed that it also possesses antineoplastic activities and has a synergistic action when combined with other chemotherapeutic agents. It acts via several mechanisms to prevent tumour growth, including inhibition of the Hedgehog pathway, prevention of angiogenesis, decreased endothelial cell proliferation, cell cycle arrest and induction of auto-phagocytosis. These allow itraconazole, either alone or in combination with other cytotoxic agents, to increase drug efficacy and overcome drug resistance. This study reviews the reported literature on the use of itraconazole in a variety of malignancies and highlights the recent insights into the critical pathways acted upon to prevent tumour growth.
\end{abstract}

\section{Contents}

1. Background

2. Itraconazole and the Hedgehog pathway

3. Itraconazole and angiogenesis

4. Itraconazole and drug resistance

5. Clinical papers

6. Conclusion

\section{Background}

The repurposing of drugs is becoming increasingly attractive as it avoids the expense and time required to develop novel therapeutics (1-3). Itraconazole is a Food and Drug

Correspondence to: Dr Rachel Pounds, Obstetrics and Gynaecology Department, Birmingham Women's Hospital, Mindelsohn Way, Edgbaston, Birmingham B15 2TG, UK

E-mail: rachel.pounds@nhs.net

Key words: itraconazole, malignancy, hedgehog pathway, angiogenesis, drug resistance
Administration-approved agent that has passed toxicity testing, has recognised anti-neoplastic properties and has already been assessed in cancer therapy $(4,5)$.

The original function of itraconazole was as a broad-spectrum anti-fungal agent that inhibits lanosterol 14- $\alpha$-demethylase (14LDM), an enzyme that produces ergosterol in fungi and cholesterol in mammals (4-8). It is used to treat fungal infections, including aspergillosis, candidiasis and histoplasmosis, and for prophylaxis in immunosuppressive disorders $(9,10)$. Itraconazole is a relatively safe drug, with rare side effects, including neutropenia, liver failure and heart failure (9).

An emerging body of in vivo, in vitro and clinical evidence has confirmed that itraconazole possesses antineoplastic activity and has a synergistic action when combined with other chemotherapeutic agents (4-33). It acts via several underlying mechanisms to prevent tumour growth (Fig. 1), including inhibition of the Hedgehog pathway, prevention of angiogenesis, decreased endothelial cell proliferation, cell cycle arrest, reversal of drug resistance and induction of auto-phagocytosis (9-11). Itraconazole's ability to prevent angiogenesis appears to be associated with its anti-fungal properties, yet all other mechanisms are not associated with the inhibition of 14LDM $(4-8,12)$.

This paper reviews the currently available literature regarding the use of itraconazole in a variety of malignancies. A literature search was performed using PubMed with the keywords 'Itraconazole and Cancer' from January 1987 to October 2016. Those articles with titles relevant to our review topic were assessed for eligibility; abstracts that either described the clinical use of itraconazole as a cancer treatment in patients or illustrated evidence of itraconazole's antineoplastic activity from in vivo or in vitro studies were included. These selected articles were obtained and analysed in full, with 31 included in our review. Fig. 2 demonstrates the articles initially identified and those included for the review of the literature.

\section{Itraconazole and the Hedgehog pathway}

The Hedgehog pathway controls necessary developmental and embryogenic processes that are involved in tissue patterning and morphogenesis $(4,11,13)$. While essentially quiescent in adult tissues, the Hedgehog pathway is involved in the maintenance of certain epithelial progenitor cell 
populations and is activated during tissue regeneration and wound healing $(4,13)$. In the absence of Sonic Hedgehog ligand (Shh), patched 1 (PTCH1) represses the activity of smoothened (SMO), and the pathway is turned off. Binding of Shh ligand to PTCH1 relieves its suppression of SMO, resulting in protein stabilisation and nuclear translocation of the GLI transcription factors (34-36). The GLI proteins, of which there are three (GLI1-3), activate a plethora of downstream targets that effect cell growth, survival and differentiation (37). In the majority of situations, expression of GLI1 mRNA is used as a surrogate marker for Hedgehog pathway activity (4). Fig. 3 depicts the Hedgehog signalling pathway, when activated and supressed.

Abnormalities in Hedgehog signalling can result in congenital malformations, and inappropriate activation of the pathway may lead to the development of cancer $(4,11)$. In addition to the overexpression of Shh, Hedgehog pathway activation may follow loss-of-function of PTCH1, gain-of-function mutations in SMO and epigenetic modulation of key pathway components, such as suppressor of fused, which is a negative regulator of the Hedgehog pathway (11).

Thus far, drugs designed to treat Hedgehog-driven malignancies have been developed to target SMO, although other compounds have been identified to inhibit or modulate the activity of the GLI proteins (38). Drugs demonstrated to block the Hedgehog pathway include vismodegib (GDC-0449), sonidegib (LDE-225) and cyclopamine (39). These drugs are known to act by binding to and antagonising the function of SMO $(4,11,14)$. Itraconazole similarly inhibits the Hedgehog pathway by acting directly on SMO but, unlike other drugs, it binds to a different site on the SMO protein $(4,11)$. This is the likely explanation for its synergistic activity with other anti-neoplastic agents, such as vismodegib. Itraconazole can therefore be used in combination with or, in cases of drug resistance, as an alternative to other Hedgehog pathway inhibitors (4). When other signalling pathways facilitate neoplastic growth, tumours may survive even in the presence of Hedgehog pathway inhibition, and therefore, a combination of drugs acting on multiple pathways may be required (14).

Evidence from pre-clinical studies has confirmed the capacity of itraconazole to inhibit the Hedgehog pathway $(4,12,13,15,16)$. Treatment of allografted medulloblastomas in a murine model resulted in a reduction in GLI1 mRNA and growth suppression (4). When combined with cyclopamine the effect was greater than with itraconazole treatment alone $(4,11)$. Shh and GLI1 expression was revealed in low grade, stage 1A human endometrial cancer tissue samples (15). In vitro cell proliferation was then significantly inhibited by itraconazole, even when cells were treated with an oral anti-fungal dose (15). In cultured pleural mesothelioma cells, activated Hedgehog signalling was inhibited with itraconazole and arsenic trioxide, an anti-leukaemia drug, which is known to target the GLI1 protein (13). The two drugs reduced the expression of GLI1, decreased cell viability, perturbed cell cycle progression and induced apoptosis $(13,16)$. The Hedgehog pathway is aberrantly activated in basal cell carcinoma (BCC), due primarily to the presence of a mutated or inherited defective PTCH1 gene (6). Itraconazole administration reduced the growth of BCC in mouse models, decreased the expression of GLI1 mRNA and induced tumour necrosis (4).

\section{Itraconazole and angiogenesis}

The growth of solid tumours is angiogenesis-dependent (8). Anti-angiogenic agents are used in cancer therapy, and itraconazole has been shown to act on numerous pathways necessary for angiogenesis (8). It inhibits vascular endothelial growth factor (VEGF) signalling by preventing VEGF binding to the VEGF receptor 2, thereby reducing endothelial cell proliferation $(5,17)$. Itraconazole can also prevent cell migration, chemotaxis and tube formation, all of which are essential for neovascularisation and angiogenesis (8).

The suppression of tumour growth with itraconazole treatment has been demonstrated in non-small cell lung cancer xenografts $(8,18)$. In one such study, growth was reduced by 72 and $79 \%(\mathrm{P}<0.001)$ in two primary xenograft models (8). Greater tumour growth suppression was observed with combination therapy involving itraconazole and cisplatin (8). As well as inhibiting cell proliferation in response to angiogenesis factors (VEGF and fibroblast growth factor), the migration and formation of tube networks were also prevented. These are necessary for capillary bed production; therefore, the area of tumour vascularity significantly decreased $(8,18)$. In addition, itraconazole has been demonstrated to reduce pleural effusion volumes, the number of pleural tumour foci and VEGF-C levels in xenograft models with Lewis lung carcinoma (7).

\section{Itraconazole and drug resistance}

Drug resistance is a major obstacle in the desire to cure malignancies (33). Combination therapy is believed to reduce the development of drug resistance when compared with treatment with one drug alone $(40,41)$. It is therefore possible that itraconazole can prevent the resistance associated with monotherapy when combined with other medications. Furthermore, all opportunities in reversing resistance should be explored, particularly with therapies that have minimal sequela, such as itraconazole. It has been revealed in vitro to reverse multi-drug resistance in numerous types of malignancies (9). In ovarian and breast cancer, drug resistance to chemotherapy is associated with permeability glycoprotein (also termed p-glycoprotein), multidrug resistance protein 1 and ATP-binding cassette sub-family B member $1(14,18)$. This is an efflux pump present on cell membranes that reduces intracellular drug concentrations, conferring cellular resistance to genotoxic therapies (42). Ovarian clear cell carcinoma, one of the more aggressive disease subtypes, has been identified to have increased expression of these efflux pumps, thereby preventing the accumulation of cytotoxic agents within the malignant cells (43). In vitro studies confirm that itraconazole inhibits the efflux pump, thus reversing resistance $(10,14,19,20)$. This has also been observed in resistant leukaemia and human embryonic kidney cells $(21,22)$. 


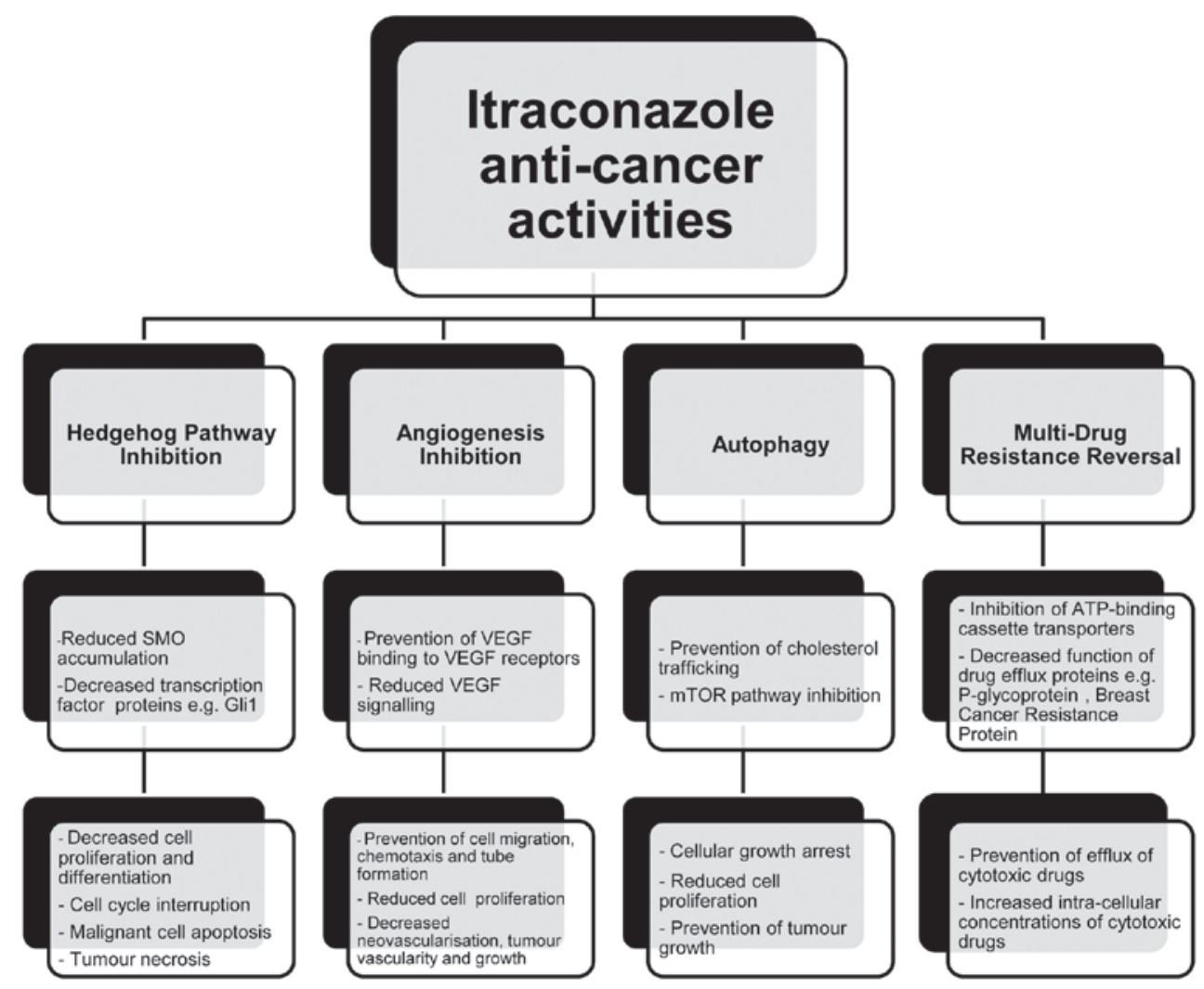

Figure 1. The anti-neoplastic activities of itraconazole. A diagram demonstrating the anti-neoplastic activities of itraconazole: Hedgehog pathway inhibition; angiogenesis inhibition; autophagy; multi-drug resistance reversal. VEGF, vascular endothelial growth factor; mTOR, mechanistic target of rapamycin; SMO, smoothened.

Flow Diagram of Literature Search
Articles identified from a PubMed search using keywords "Itraconazole and Cancer" in the timeframe 01.01.1987-31.10.2016.
$\mathrm{N}=\mathbf{8 1 6}$

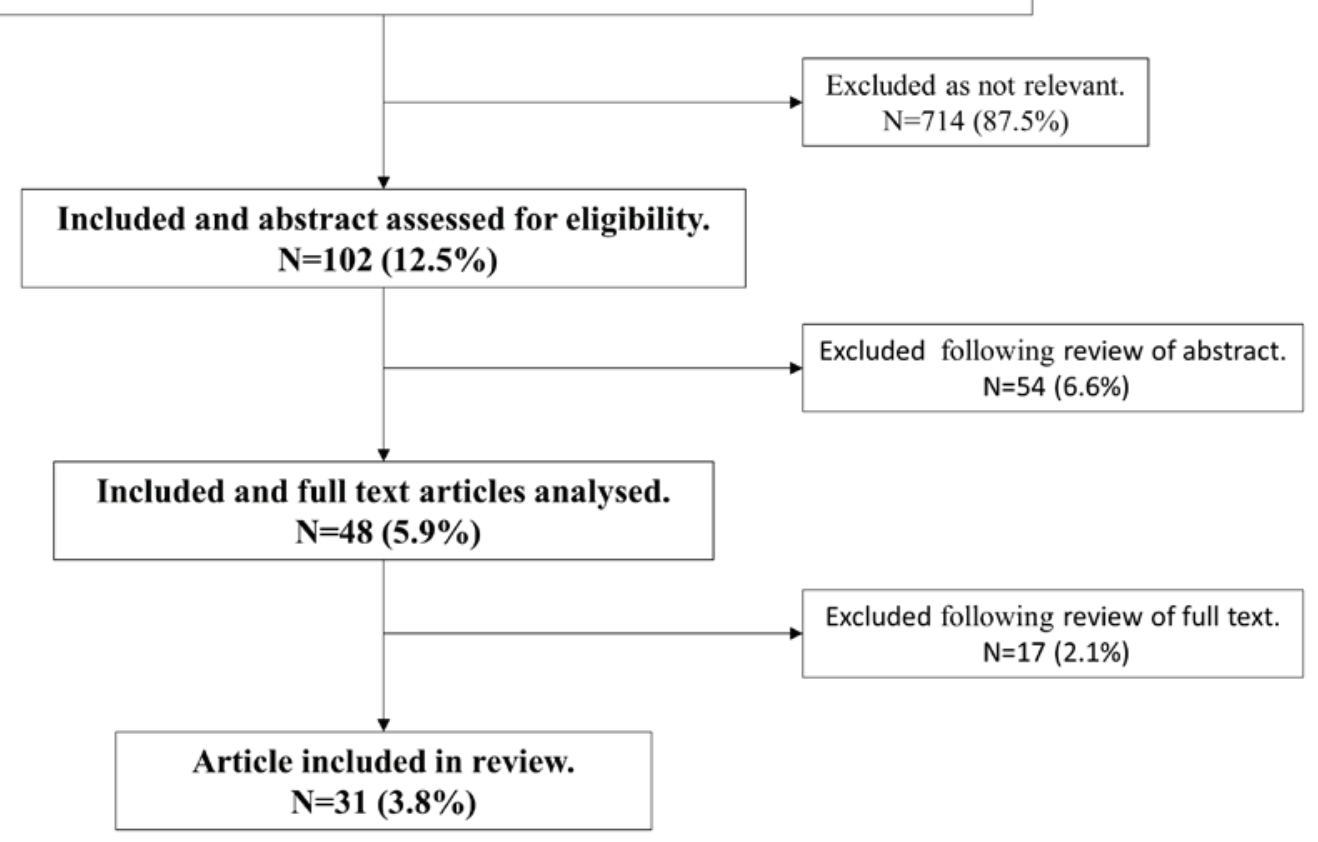

Figure 2. Flow diagram of the literature search. Articles identified, analysed and included in literature review. 


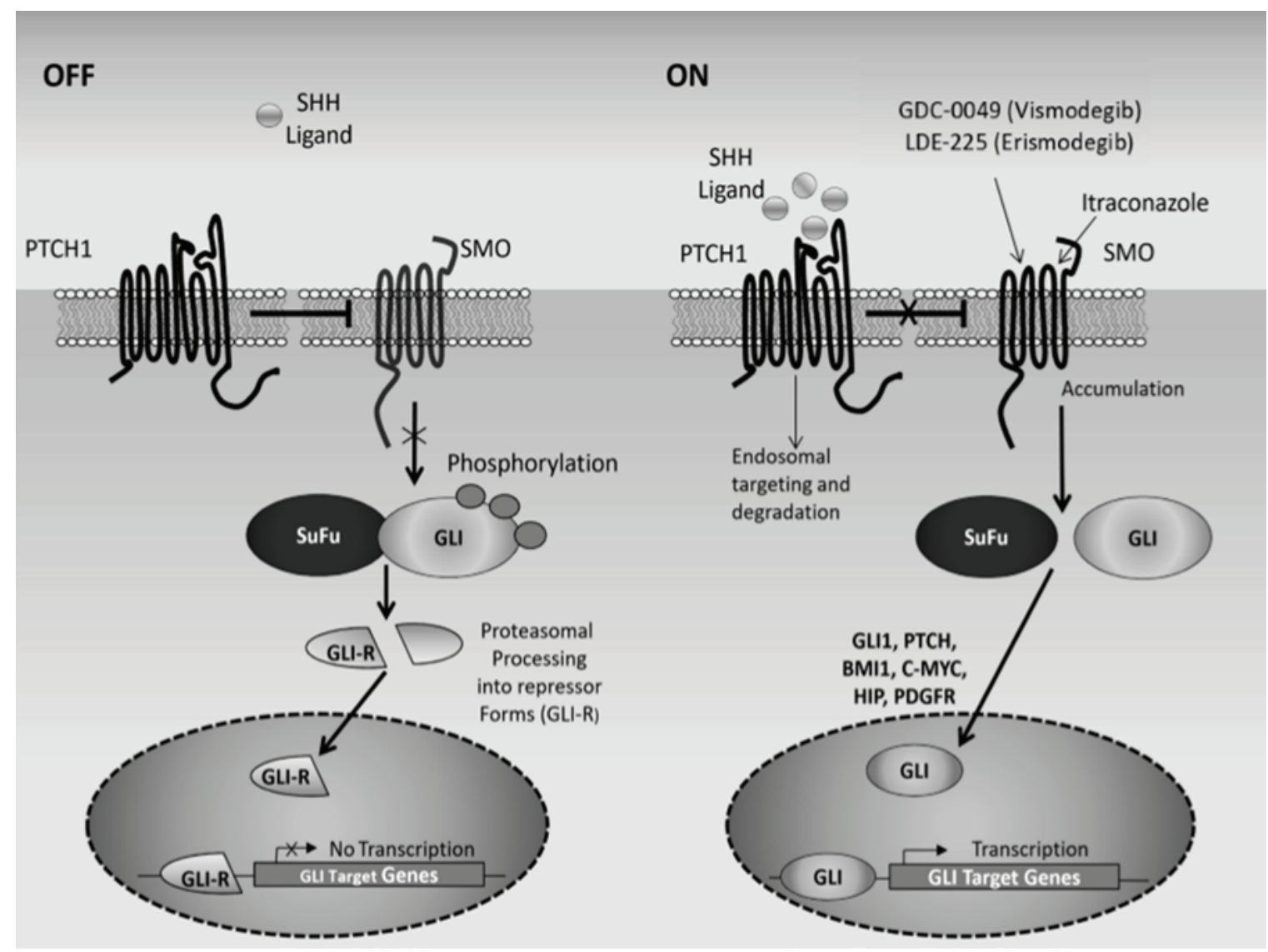

Figure 3. Schematic representation of the Hedgehog signaling pathway. In the absence of Shh, PTCH1 suppresses the activity of SMO. SuFu induces proteasomal degradation of the GLI (glioma-associated oncogene) transcription factors. The cleaved GLI factors, GLI-R (GLI repressor form), translocate to the nucleus where they suppress the expression of Hedgehog target genes. In this setting, the pathway is turned off. In the presence of Shh, PTCH1 suppression of SMO is relieved, which modulates SuFu activity. SuFu no longer associates with the GLI transcription factors, which translocate to the nucleus, activating Hedgehog target genes. These include pathway effectors (GLI1) and regulators (PTCH1 and HIP), and proteins involved in cell proliferation (PDGRF, cyclin D2, BMI1 (B-cell-specific Moloney murine leukemia virus integration site 1) and c-MYC). Hedgehog pathway inhibitors referred to include GDC-0449 (vismodegib), LDE225 (erismodegib) and itraconazole, which directly inhibit SMO. Shh, Sonic Hedgehog ligand; PTCH1, patched 1; SMO, smoothened; SuFu, suppressor of fused; HIP, Hedgehog interacting protein; PDGFR, platelet-derived growth factor receptor.

\section{Clinical papers}

The use of itraconazole as a therapy has received extensive attention, primarily in phase I/II studies. Details of recent clinical studies are presented in Table I.

Ovarian cancer. At presentation, ovarian cancer is at an advanced stage in $70-75 \%$ of patients, and has a 5 -year survival rate of $\sim 40 \%(44,45)$. Although the initial response rates to first line chemotherapy are high, resistance is common, as reflected by poor survival (46). Itraconazole has been utilised in refractory disease to try and reverse such chemo-resistance $(19,23)$. In a retrospective review, 55 patients were treated either with chemotherapy alone (regimes of pegylated liposomal doxorubicin, gemcitabine, docetaxel, irinotecan or paclitaxel) or chemotherapy (docetaxel based in 79\%) combined with itraconazole. The combination therapy was given biweekly to 19 female patients, with 400-600 mg itraconazole administered daily for 4 or 5 days. The median progression-free survival time was significantly longer for those receiving itraconazole (103 days, compared with 53 days in those who did not receive itraconazole; $\mathrm{P}=0.014)$, as was the overall survival time (642 days, compared with 139 days in those who did not receive itraconazole; $\mathrm{P}=0.0006)$. The overall response rate following treatment was $18 \%$, with a greater proportion of the itraconazole group exhibiting a response (32\% in the itraconazole group, $11 \%$ in the control group). The continued use of itraconazole is the likely explanation for the improved survival rates (23).

In another study (19), 9 patients with recurrent clear cell ovarian cancer had itraconazole added to their treatment regime with the objective of improving chemotherapeutic efficacy. Itraconazole $400 \mathrm{mg}$ daily was administered over 4 days every 2 weeks. A response rate of $44 \%$ was achieved, with a higher median overall survival time (1,047 days) compared with that previously reported in other studies, which ranged between 7 and 10 months $(47,48)$.

As chemotherapy is typically discontinued following resistance, few patients with refractory disease are eligible for such studies, and small numbers of female patients included (49). Another limitation is that cytotoxic regimens differ between patients, doses are frequently altered and patients are not randomised.

Prostate cancer. In advanced prostate cancer, although androgen deprivation therapy can be successful, inevitably resistance will develop (50). When this occurs, therapeutic options are limited. A subsequent randomised phase II trial 


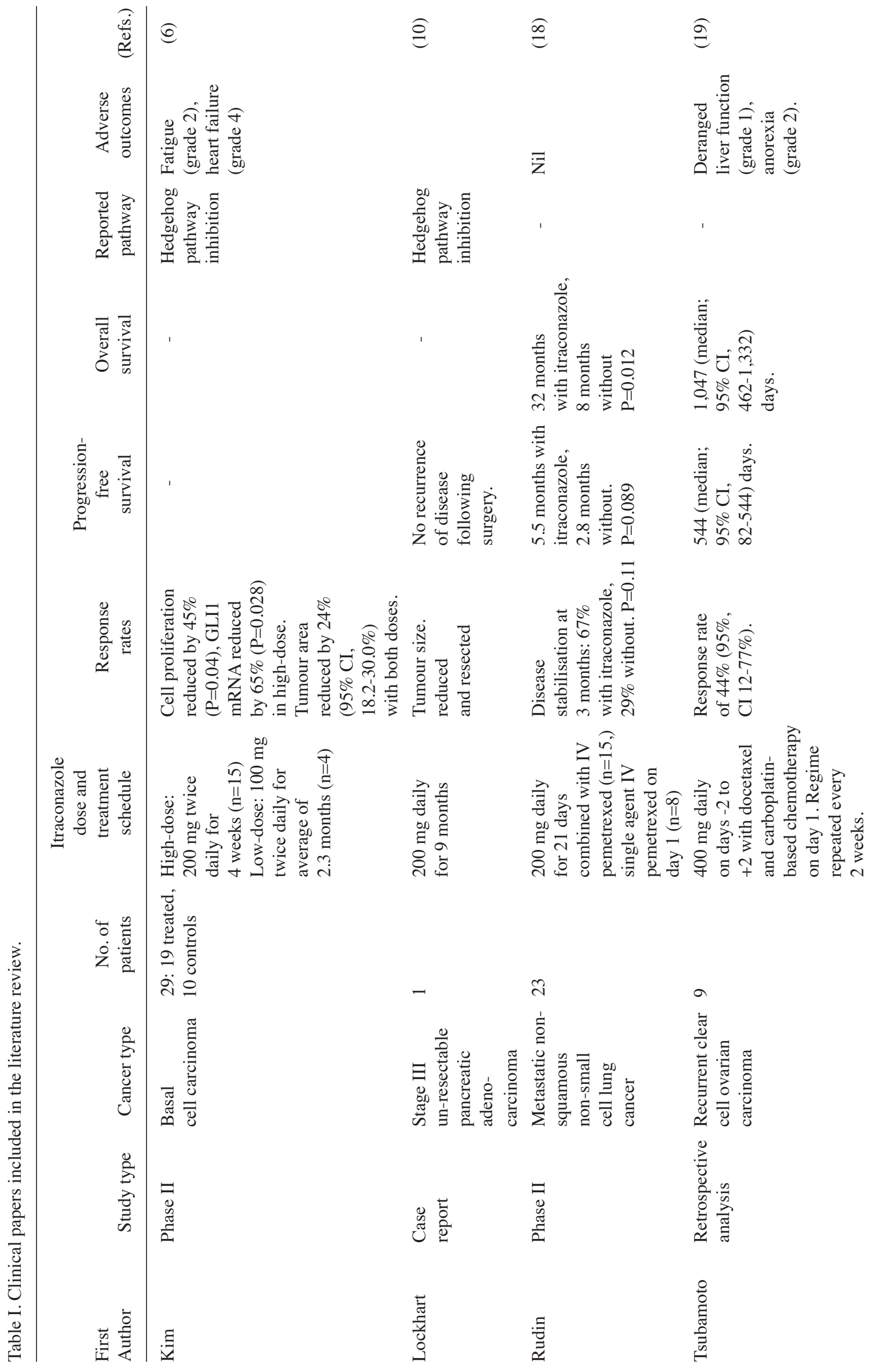




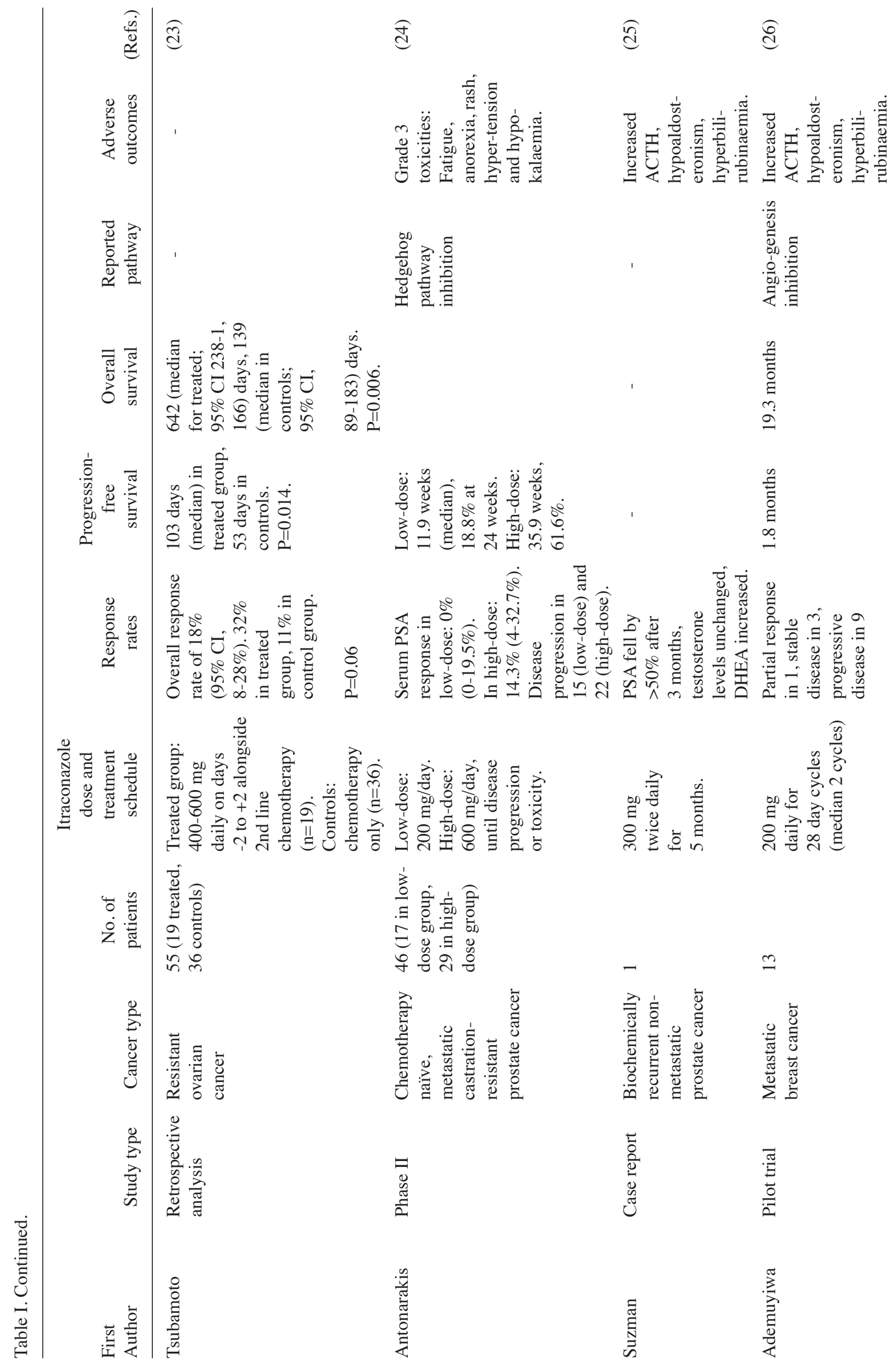




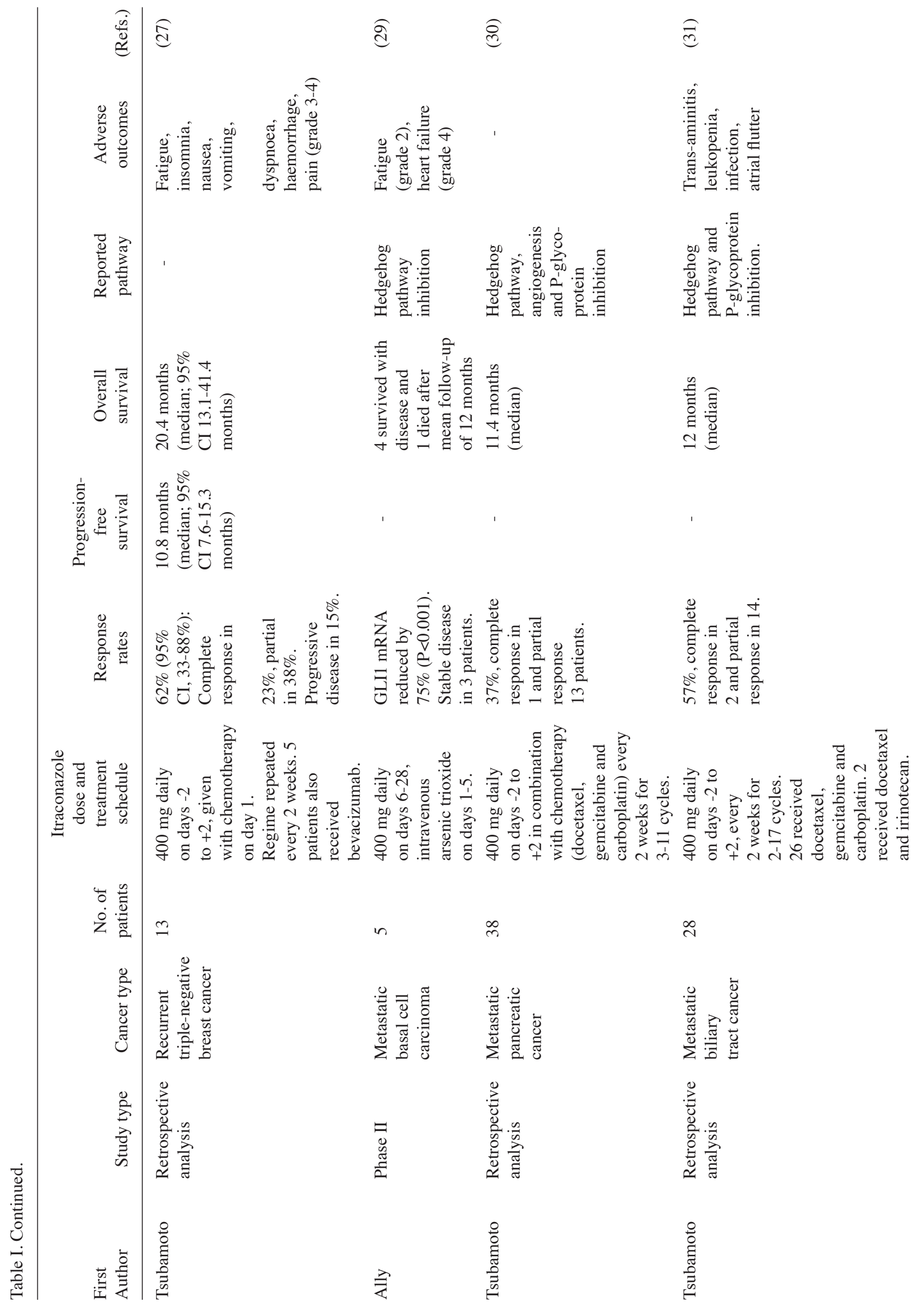


explored the use of either 200 or $600 \mathrm{mg}$ itraconazole daily for the treatment of metastatic castration-resistant prostate cancer in 46 patients (24). The higher dose increased progression-free survival times and prostate-specific antigen (PSA) progression-free survival rates. In addition, skin biopsies exhibited a down-modulation of GLI1 (reflecting inhibition of the Hedgehog pathway) in the two treatment arms, which was associated with a significantly longer median PSA progression-free survival time (24).

A further case report describes the use of high dose itraconazole (300 mg twice daily) to treat a biochemical recurrence following radical prostatectomy in non-metastatic disease (25). After the patient declined castration treatment, itraconazole was administered and the PSA level reduced by $>50 \%$ in 3 months. Although the PSA continued to decline during an additional 2 months of treatment, levels began to rise upon termination of the therapy (25). As such, itraconazole may be an alternative therapy for those wishing to avoid castrating or cytotoxic therapy, although additional trials are required to confirm this $(24,25)$.

Breast cancer. A pilot trial evaluated the pharmacokinetics of itraconazole when administered to 13 patients with metastatic breast cancer (26). As the plasma levels of itraconazole increased, higher levels of thrombospondin-1, which inhibits angiogenesis, were detected. In addition, the levels of other angiogenic factors, basic fibroblast growth factor and placenta-derived growth factor decreased, albeit lacking a direct association between the fall in angiogenic factors and itraconazole levels.

In another study, 13 patients with progressive triple-negative breast cancer, despite extensive chemotherapy, were administered itraconazole (27). Patients commenced itraconazole treatment ( $400 \mathrm{mg}$ daily for 4 days, repeated every 2 weeks) alongside cytotoxic agents, with 5 patients also receiving bevacizumab. Response rates were high (62\%), with $23 \%$ complete responses. Overall survival rates were advantageous compared with previous findings of itraconazole use. Earlier studies of triple-negative disease failed to demonstrate such improvements: A phase III trial using bevacizumab and a retrospective analysis of platinum-based chemotherapy did not reveal overall survival benefits, while a meta-analysis identified only short-term improvements with platinum-based chemotherapy in non-metastatic disease (51-53).

Lung cancer. Itraconazole has been analysed as a second line treatment in metastatic non-squamous non-small cell lung cancer (18). A phase II study on 23 patients randomised to either single agent pemetrexed or combined pemetrexed and itraconazole (200 mg daily for 21 day cycles) reported the anticipated response rates in the pemetrexed only arm, with improved outcomes in those exposed to itraconazole (18). The proportion with disease stabilisation at 3 months was higher, median progression-free survival increased and overall survival was greater compared to those treated with pemetrexed alone. Future trials will explore its use as a first line treatment alongside other agents.

$B C C$. BCC, the most common form of skin cancer, has been a focus for Hedgehog pathway inhibitors $(6,28,29,54,55)$. 
Studies using vismodegib, sonidegib and itraconazole to treat $\mathrm{BCC}$ have all demonstrated efficacious results; however, resistance is frequently problematic $(6,28,29,55-58)$. One phase II trial compared high dose itraconazole (200 mg twice daily for 4 weeks) with a control group, demonstrating a reduction in cell proliferation (Ki-67) and Hedgehog pathway activity (GLI1 mRNA levels) with itraconazole (6). The tumour area decreased when treated with either the high dose or with a lower dose over a longer time period (100 mg twice daily for 1-4 months). The findings were not replicated in those with prior vismodegib exposure, questioning the value of itraconazole following resistance to this drug (6).

Another review also determined that clinical responses were limited following vismodegib resistance (29). A total of 5 patients with metastatic BCC were treated with combined itraconazole (400 mg daily on days 6-28) and intravenous arsenic trioxide (on days 1-5). Despite a $75 \%$ decrease in GLI1 mRNA levels, a reduction in tumour size was not evident. While vismodegib and sonidegib appear to provide higher response rates and greater Hedgehog pathway inhibition, it may be beneficial to use itraconazole following resistance or as a combined therapy. It remains unclear whether continuous high dose itraconazole administered over a longer period could give similar results to those observed with vismodegib and sonidegib $(6,28,29)$.

Pancreatic cancer. In a previous study (30), 38 patients with progressive pancreatic cancer received itraconazole (400 mg daily for 4 days) in combination with chemotherapy (docetaxel, gemcitabine and carboplatin) over 2 week cycles. A response rate of $37 \%$ was achieved, with complete and partial responses in 1 and 13 patients, respectively. In total, 35 patients who either had stable disease or had a complete or partial response continued itraconazole treatment with irinotecan-based chemotherapy. The response rate increased to $47 \%$, with a median overall survival time of 11.4 months. This was greater than the median overall survival time of 6 months found in an earlier analysis of clinical trials that investigated second-line treatment in advanced pancreatic disease (59). The advantageous results in this study are possibly due to the administration of triple chemotherapeutic agents.

A serendipitous case of pancreatic cancer treated by itraconazole has previously been reported (10). Histoplasmosis infection was detected in a patient with stage III locally advanced unresectable pancreatic adenocarcinoma. Palliative chemotherapy was paused, a 9-month course of itraconazole $200 \mathrm{mg}$ daily commenced and, upon completion, the tumour was revealed to have decreased in size. It was deemed resectable and following surgery the patient remained disease free, with no evidence of recurrence. As chemotherapy had been withheld, the reduction was thought to have been caused by itraconazole and Hedgehog pathway inhibition.

Biliary tract cancer. Biliary tract cancer is a rare condition and has a poor prognosis (60). Favourable response rates and acceptable toxicity effects have been demonstrated in a study of patients with refractory metastatic biliary tract carcinoma treated with itraconazole (31). A total of 28 patients received itraconazole (400 mg daily for 4 days) in addition to chemotherapy regimens (docetaxel, gemcitabine and carboplatin in 26 patients, docetaxel and irinotecan in 2 patients). A complete response was observed in 2 patients, while 14 had a partial response. The overall response rate was $57 \%$ and the median overall survival time was 12 months. This compares to 7.2 months in a systematic review of second-line treatment for advanced biliary tract carcinoma (61). Despite the small number of patients in this study, itraconazole appears to be a promising therapeutic alternative after first-line treatment in recurrent disease.

Mycosis fungoides. Another study on successful itraconazole treatment is that of a patient with Mycosis fungoides (32), the most common type of cutaneous T-cell lymphoma. The patient developed erythematous plaques on four separate occasions, yet no cause was identified. Following no improvement with miconazole or topical steroids, itraconazole $200 \mathrm{mg}$ daily was administered for 7 days. The lesions completely resolved and additional episodes again only responded following itraconazole treatment. Eventually biopsy and histology results supported a diagnosis of Mycosis fungoides. The mechanism of action in this condition is unclear.

Acute leukaemia. As previously stated, itraconazole is used for fungal infection prophylaxis in immunosuppressive conditions (9). In patients with acute leukaemia it is often administered for prophylactic purposes in those receiving chemotherapy $(33,62)$. Resistance to the cytotoxic agent daunorubicin has been reversed by itraconazole (63). It has been demonstrated that the addition of itraconazole $(100 \mathrm{mg}$ twice daily) improves remission rates in acute myelogenous leukaemia and disease-free survival in acute lymphoblastic leukaemia (33). This supports itraconazole's action of reversing drug resistance and is considered to be associated with its involvement with cytochrome P-450 and P-glycoprotein.

\section{Conclusion}

There is understandable reticence regarding the repurposing of drugs. Although the initial focus of these therapies is to treat non-malignant disease, the principle of cell destruction and elimination is the same as in agents created to target malignancy. To have a drug acting singularly on a recognised essential pathway in the malignant process is ideal, but, in reality, few drugs act in such a manner. Thus, the use of therapies with multiple targets would be reasonable to explore.

Treatments that cause fewer adverse effects, give greater survival benefits and are more cost-effective are greatly required (8). Itraconazole has been shown to be safe in humans and is cheap to purchase, thus making it a viable option for future studies $(9,23)$. By avoiding the lengthy process and cost-implications associated with bringing a novel drug to market, further study into its actions and potential benefits make it an attractive prospect.

Evidence from in vivo, in vitro and clinical studies have demonstrated the antineoplastic effects of itraconazole and have revealed at a number of the critical pathways that it targets (4-33). These results allow itraconazole, alone or in combination with other chemotherapeutic agents, to increase drug efficacy and overcome drug resistance. Exploration in aggressive and refractory disease, including ovarian cancer, 
with greater participant numbers and consistent treatment regimens is required. While trials are currently underway and additional studies are planned, studies need to use itraconazole in combination with other drugs affecting cell survival. They need to use itraconazole over longer time periods, at various stages of disease, in tumours associated with drug resistance and in other malignancies known to be affected by the Hedgehog pathway and angiogenesis $(9,10)$.

\section{Acknowledgements}

This review was supported by Ovacome, The Ovarian Cancer Support Charity.

\section{References}

1. Chong CR and Sullivan DJ Jr: New uses for old drugs. Nature 448: 645-646, 2007.

2. Pantziarka P, Bouche G, Meheus L, Sukhatme V, Sukhatme VP and Vikas P: The repurposing drugs in oncology (ReDO) project. Ecancermedicalscience 8: 442, 2014.

3. DiMasi JA, Hansen RW and Grabowski HG: The price of innovation: New estimates of drug development costs. J Health Econ 22: 151-185, 2003

4. Kim J, Tang JY, Gong R, Kim J, Lee JJ, Clemons KV, Chong CR, Chang KS, Fereshteh M, Gardner D, et al: Itraconazole, a commonly used antifungal that inhibits Hedgehog pathway activity and cancer growth. Cancer Cell 17: 388-399, 2010.

5. Navec BA, Grassi P, Dell A, Haslam SM and Liu JO: The antifungal drug itraconazole inhibits vascular endothelial growth factor receptor 2 (VEGFR2) glycosylation, trafficking, and signalling in endothelial cells. J Biol Chem 286: 44045-44056, 2011.

6. Kim DJ, Kim J, Spaunhurst K, Montoya J, Khodosh R, Chandra K, Fu T, Gilliam A, Molgo M, Beachy PA and Tang JY: Open-label, exploratory phase II trial of oral itraconazole for the treatment of basal cell carcinoma. J Clin Oncol 32: 745-751, 2014.

7. Wang Y, Yao Y, Liu H, Ma X, Lv T, Yuan D, Xiao X, Yin J and Song Y: Itraconazole can inhibit malignant pleural effusion by suppressing lymphangiogenesis in mice. Transl Lung Cancer Res 4: 27-35, 2015.

8. Aftab BT, Dobromilskaya I, Liu JO and Rudin CM: Itraconazole inhibits angiogenesis and tumor growth in non-small cell lung cancer. Cancer Res 71: 6764-6772, 2011.

9. PantziarkaP, Sukhatme V,Bouche G,Meheus L and Sukhatme VP: Repurposing drugs in oncology (ReDO)-itraconazole as an anti-cancer agent. Ecancermedicalscience 9: 521, 2015.

10. Lockhart NR, Waddell JA and Schrock NE: Itraconazole therapy in a pancreatic adenocarcinoma patient: A case report. J Oncol Pharm Pract 22: 528-532, 2016.

11. Dirix L: Discovery and exploitation of novel targets by approved drugs. J Clin Oncol 32: 720-721, 2014.

12. Pace JR, DeBerardinis AM, Sail V, Tacheva-Grigorova SK Chan KA, Tran R, Raccuia DS, Wechsler-Reya RJ and Hadden MK: Repurposing the clinically efficacious antifungal agent itraconazole as an anticancer chemotherapeutic. J Med Chem 59: 3635-3649, 2016.

13. You M, Varona-Santos J, Singh S, Robbins DJ, Savaraj N and Nguyen DM: Targeting the hedgehog signal transduction pathway suppresses survival of malignant pleural mesothelioma cells in vitro. J Thorac Cardiovasc Surg 147: 508-516, 2014.

14. Kast RE, Karpel-Massler G and Halatsch ME: CUSP9* treatment protocol for recurrent glioblastoma: Aprepitant, artesunate, auranofin, captopril, celecoxib, disulfiram, itraconazole, ritonavir, sertraline augmenting continuous low dose temozolomide. Oncotarget 5: 8052-8082, 2014.

15. Inoue K, Tsubamoto H, Sakata K, Sakane R, Hao H, Hirota S, Sonoda T and Shibahara H: Expression of hedgehog signals and growth inhibition by itraconazole in endometrial cancer. Anticancer Res 36: 149-153, 2016.

16. Kim J, Aftab BT, Tang JY, Kim D, Lee AH, Rezaee M, Kim J, Chen B, King EM, Borodovsky A, et al: Itraconazole and arsenic trioxide inhibit Hedgehog pathway activation and tumor growth associated with acquired resistance to smoothened antagonists. Cancer Cell 23: 23-34, 2013.
17. Chong CR, Xu J, Lu J, Bhat S, Sullivan DJ Jr and Liu JO: Inhibition of angiogenesis by the antifungal drug itraconazole. ACS Chem Biol 2: 263-270, 2007.

18. Rudin CM, Brahmer JR, Juergens RA, Hann CL, Ettinger DS, Sebree R, Smith R, Aftab BT, Huang P and Liu JO: Phase 2 study of pemetrexed and itraconazole as second-line therapy for metastatic nonsquamous non-small cell lung cancer. J Thorac Oncol 8: 619-623, 2013

19. Tsubamoto H, Sonoda T, Yamasaki M and Inoue K: Impact of combination chemotherapy with itraconazole on survival for patients with recurrent or persistent ovarian clear cell carcinoma. Anticancer Res 34: 2007-2014, 2014.

20. Takara K, Tanigawara Y, Komada F, Nishiguchi K, Sakaeda T and Okumura K: Cellular pharmacokinetic aspects of reversal effect of itraconazole on P-glycoprotein-mediated resistance of anticancer drugs. Biol Pharm Bull 22: 1355-1359, 1999.

21. Gupta A, Unadkat JD and Mao Q: Interactions of azole antifungal agents with the human breast cancer resistance protein (BCRP). J Pharm Sci 96: 3226-3235, 2007.

22. Kurosawa M, Okabe M, Hara N, Kawamura K, Suzuki S, Sakurada K and Asaka M: Reversal effect of itraconazole on adriamycin and etoposide resistance in human leukemia cells. Ann Hematol 72: 17-21, 1996.

23. Tsubamoto H, Sonoda T, Yamasaki M and Inoue K: Impact of combination chemotherapy with itraconazole on survival of patients with refractory ovarian cancer. Anticancer Res 34: 2481-2487, 2014.

24. Antonarakis ES, Heath EI, Smith DC, Rathkopf D, Blackford AL, Danila DC, King S, Frost A, Ajiboye AS, Zhao M, et al: Repurposing itraconazole as a treatment for advanced prostate cancer: A noncomparative randomised phase II trial in men with metastatic castration-resistant prostate cancer. Oncologist 18: 163-173, 2013.

25. Suzman DL and Antonarakis ES: High-dose itraconazole as a noncastrating therapy for a patient with biochemically recurrent prostate cancer. Clin Genitourin Cancer 12: e51-e53, 2014.

26. Ademuyiwa FO, Zhao Q, Perkins SM, Gebregziabher N, Jones DR, Vaughn LG, Sledge GW and Miller K: A pilot trial of itraconazole pharmacokinetics in patients with metastatic breast cancer. J Clin Oncol 29 (15 Suppl): e13565, 2011.

27. Tsubamoto H, Sonoda $\mathrm{T}$ and Inoue K: Impact of itraconazole on the survival of heavily pre-treated patients with triple-negative breast cancer. Anticancer Res 34: 3839-3844, 2014.

28. Wahid M, Jawed A, Mandal RK, Dar SA, Khan S, Akhter N and Haque S: Vismodegib, itraconazole and sonidegib as hedgehog pathway inhibitors and their relative competencies in the treatment of basal cell carcinomas. Crit Rev Oncol Hematol 98: 235-241, 2016.

29. Ally MS, Ransohoff K, Sarin K, Atwood SX, Rezaee M, Bailey-Healy I, Kim J, Beachy PA, Chang AL, Oro A, et al: Effects of combined treatment with arsenic trioxide and itraconazole in patients with refractory metastatic basal cell carcinoma. JAMA Dermatol 152: 452-456, 2016.

30. Tsubamoto $\mathrm{H}$, Sonoda $\mathrm{T}$, Ikuta $\mathrm{S}$, Tani $\mathrm{S}$, Inoue $\mathrm{K}$ and Yamanaka N: Combination chemotherapy with itraconazole for treating metastatic pancreatic cancer in the second-line or additional setting. Anticancer Res 35: 4191-4196, 2015.

31. Tsubamoto H, Sonoda T, Ikuta S, Tani S, Inoue $\mathrm{K}$ and Yamanaka N: Impact of itraconazole after first-line chemotherapy on survival of patients with metastatic biliary tract cancer. Anticancer Res 35: 4923-4927, 2015.

32. Cooper SM, Sheridan A and Burge S: Mycosis fungoides responding to systemic itraconazole. J Eur Acad Dermatol Venereol 17: 588-590, 2003.

33. Vreugdenhil G, Raemaekers JM, van Dijke BJ and de Pauw BE: Itraconazole and multidrug resistance: Possible effects on remission rate and disease-free survival in acute leukaemia. Ann Haematol 67: 107-109, 1993.

34. Kalderon D: Transducing the hedgehog signal. Cell 103: 371-374, 2000.

35. Pasca di Magliano M and Hebrok M: Hedgehog signalling in cancer formation and maintenance. Nat Rev Cancer 3: 903-911, 2003.

36. Ruiz i Altaba A, Sánchez P and Dahmane N: Gli and hedgehog in cancer: Tumours, embryos and stem cells. Nat Rev Cancer 2: 361-372, 2002.

37. Stecca B and Ruiz I Altaba A: Context-dependent regulation of the GLI code in cancer by HEDGEHOG and non-HEDGEHOG signals. J Mol Cell Biol 2: 84-95, 2010. 
38. Rimkus TK, Carpenter RL, Qasem S, Chan M and Lo HW: Targeting the sonic hedgehog signaling pathway: Review of smoothened and GLI inhibitors. Cancers (Basel) 8: pii: E22, 2016.

39. Sekulic A and Von Hoff D: Hedgehog pathway inhibition. Cell 164: 831, 2016

40. Sarkar S, Goldgar S, Byler S, Rosenthal S and Heerboth S: Demethylation and re-expression of epigenetically silenced tumor suppressor genes: Sensitization of cancer cells by combination therapy. Epigenomics 5: 87-94, 2013.

41. Callaghan R, Luk F and Bebawy M: Inhibition of the multidrug resistance P-glycoprotein: Time for a change of strategy? Drug Metab Dispos 42: 623-631, 2014.

42. Undevia SD, Gomez-Abuin G and Ratain MJ: Pharmacokinetic variability of anticancer agents. Nat Rev Cancer 5: 447-458, 2005.

43. Itamochi H, Kigawa J, Sultana H, Iba T, Akeshima R, Kamazawa S, Kanamori Y and Terakawa N: Sensitivity to anticancer agents and resistance mechanisms in clear cell carcinoma of the ovary. Jpn J Cancer Res 93: 723-728, 2002.

44. Maringe C, Walters S, Butler J, Coleman MP, Hacker N, Hanna L, Mosgaard BJ, Nordin A, Rosen B, Engholm G, et al: Stage at diagnosis and ovarian cancer survival: Evidence from the international cancer benchmarking partnership. Gynecol Oncol 127: $75-82,2012$.

45. Cancer research UK cancer statistics, ovarian cancer survival statistics. Available at: http://www.cancerresearchuk.org/healthprofessional/cancer-statistics/statistics-by-cancer-type/ovariancancer\#heading-Two. Accessed April, 2017.

46. Perez RP, Hamilton TC, Ozols RF and Young RC: Mechanisms and modulation of resistance to chemotherapy in ovarian cancer. Cancer 71 (4 Suppl): S1571-S1580, 1993.

47. Yoshino K, Enomoto T, Fujita M, Ueda Y, Kimura T, Kobayashi E, Tsutsui T and Kimura T: Salvage chemotherapy for recurrent or persistent clear cell carcinoma of the ovary: A single-institution experience for a series of 20 patients. Int J Clin Oncol 18: 148-153, 2013.

48. Kajiyama H, Shibata K, Mizuno M, Yamamoto E, Fujiwara S, Umezu T, Suzuki S, Nakanishi T, Nagasaka T and Kikkawa F: Postrecurrent oncologic outcome of patients with ovarian clear cell carcinoma. Int J Gynecol Cancer 22: 801-806, 2012.

49. Tsubaoto H, Ito Y, Kanazawa R, Wada R, Hosoda Y, Honda O, Takeyama R, Sakane R, Wakimoto Y and Shibahara H: Benefit of palliative chemotherapy and hospice enrolment in late-stage ovarian cancer patients. J Obstet Gynaecol Res 40: 1399-1406, 2014.

50. Tannock IF, de Wit R, Berry WR, Horti J, Pluzanska A, Chi KN, Oudard S, Théodore C, James ND, Turesson I, et al: Docetaxe plus prednisone or mitoxantrone plus prednisone for advanced prostate cancer. N Engl J Med 351: 1502-1512, 2004.

51. Brufsky A, Valero V, Tiangco B, Dakhil S, Brize A, Rugo HS Rivera R, Duenne A, Bousfoul N and Yardley DA: Second-line bevacizumab-containing therapy in patients with triple-negative breast cancer: Subgroup analysis of the RIBBON-2 trial. Breast Cancer Res Treat 133: 1067-1075, 2012.
52. Staudacher L, Cottu PH, Diéras V, Vincent-Salomon A, Guilhaume MN, Escalup L, Dorval T, Beuzeboc P, Mignot L and Pierga JY: Platinum-based chemotherapy in metastatic triple-negative breast cancer: The institut curie experience. Ann Oncol 22: 848-856, 2011.

53. Liu M, Mo QG, Wei CY, Qin QH, Huang Z and He J: Platinum-based chemotherapy in triple-negative breast cancer: A meta-analysis. Oncol Lett 5: 983-991, 2013.

54. American cancer society, cancer facts and figures 201s.2016. Available at: www.cancer.org/acs/groups/content/@ research/documents/document/acspc-047079.pdf. Accessed April, 2017.

55. Miller DL and Weinstock MA: Nonmelanoma skin cancer in the United States: Incidence. J Am Acad Dermatol 30: 774-778, 1994.

56. Sekulic A,Migden MR, Oro AE,Dirix L,Lewis KD, Hainsworth JD, Solomon JA, Yoo S, Arron ST, Friedlander PA, et al: Efficacy and safety of vismodegib in advanced basal-cell carcinoma. N Engl J Med 366: 2171-2179, 2012.

57. Pivotal data for Novartis' investigational compound LDE225 show marked tumor responses in advanced basal cell carcinoma, 2014. Available at:http://www.oncotrends.de/ pivotal-data-for-novartis-investigational-compound-lde225-sonidegibshow-marked-tumor-responses-in-advanced-basal-cell-carcinoma-422202 (Accessed April, 2017.

58. Migden MR, Guminski AD, Gutzmer R, Dirix LY, Lewis KD, Combemale P, Herd R, Gogov S, Yi T, Mone M, et al: Randomized, double-blind study of sonidegib (LDE225) in patients (pts) with locally advanced (La) or metastatic basal-cell carcinoma (BCC). J Clin Oncol 32: 5s, 2014.

59. Rahma OE, Duffy A, Liewehr DJ, Steinberg SM and Greten TF: Second-line treatment in advanced pancreatic cancer: A comprehensive analysis of published clinical trials. Ann Oncol 24: 1972-1979, 2013

60. Patel T: Increasing incidence and mortality of primary intrahepatic cholangiocarcinoma in the United States. Hepatology 33 1353-1357, 2001

61. Lamarca A, Hubner RA, David Ryder W and Valle JW: Second-line chemotherapy in advanced biliary cancer: A systematic review. Ann Oncol 25: 2328-2338, 2014.

62. Vreugdenhil G, Van Dijke BJ, Donnelly JP, Novakova IR, Raemaekers JM, Hoogkamp-Korstanje MA, Koster M and de Pauw BE: Efficacy of itraconazole in the prevention of fungal infections among neutropenic patients with hematologic malignancies and intensive chemotherapy. A double blind, placebo controlled study. Leuk Lymphoma 11: 353-358, 1993.

63. Gupta S, Kim J and Gollapudi S: Reversal of daunorubicin resistance in P388/ADR cells by itraconazole. J Clin Invest 87: 1467-1469, 1991. 